\title{
Biochemical Diagnosis
}

National Cancer Institute

\section{Source}

National Cancer Institute. Biochemical Diagnosis. NCI Thesaurus. Code C161837.

An indication that a patient had cancer diagnosed using biochemical markers specific to the disease. 